\title{
Sacred values in the Israeli-Palestinian conflict: resistance to social influence, temporal discounting, and exit strategies
}

\author{
Hammad Sheikh, ${ }^{1}$ Jeremy Ginges, ${ }^{1}$ and Scott $A \operatorname{tran}^{2,3,4}$ \\ ${ }^{1}$ New School for Social Research, New York, New York. ${ }^{2}$ CNRS-Institut Jean Nicod, Paris, France. ${ }^{3}$ John Jay College, \\ New York, New York. ${ }^{4}$ University of Michigan, Ann Arbor, Michigan
}

Address for correspondence: Hammad Sheikh, Department of Psychology, New School for Social Research, 80 Fifth Ave, New York, NY 10003. sheikh60@newschool.edu

\begin{abstract}
Conflicts over sacred values may be particularly difficult to resolve. Because sacred values are nonfungible with material values, standard attempts to negotiate, such as offering material incentives to compromise, often backfire, increasing moral outrage and support for violent action. We present studies with Palestinians in the West Bank and Gaza demonstrating three other ways sacred values may make conflict more intractable, focusing on what we call devoted actors, people who regard issues central to the Israel-Palestine conflict as sacred values. We show that devoted actors (1) were less amenable to social influence, (2) perceived conflict-related events in the past as well as expected events in the future to be temporally closer, and (3) were blind to individual opportunities to escape the conflict. These results suggest that sacred values may affect decision making in a number of ways, which, when combined, contribute to common defense and continuation of conflict.
\end{abstract}

Keywords: sacred values; protected values; intergroup conflict; Palestinians; devoted actors

Some conflicts appear to be extraordinarily difficult to resolve, despite apparent solutions that outside observers regard as obvious and rationally preferable for both parties. The conflict between Israel and the Palestinians is one salient example. The broad outline of the solution to this conflict-a division of the land and the creation of two states-was first proposed by the British Mandatory power and later approved by the United Nations following World War II. According to opinion polls, a permanent partition of the land roughly along the 1948 armistice borders is currently endorsed by most Israelis and Palestinians. Why are conflicts like this so difficult to resolve? Dominant opinion within political science argues that wars are best understood through the lens of instrumental rationality, ${ }^{1-3}$ and that apparent intractability despite the presence of a clear solution is caused by things such as imperfect information or commitment problems. ${ }^{4,5}$

In this article, we summarize a body of work and present some new empirical findings that suggest the above reasoning is insufficient. This is because many human conflicts involve things that we and others have called sacred values. ${ }^{6}$ When people construe issues central to a conflict as sacred values, they become devoted actors: ${ }^{7}$ avoiding the rational logic of realpolitik, ${ }^{8}$ game-theoretic analyses, ${ }^{9}$ or the marketplace (i.e., rational actors seeking the most cost-effective means to achieve a specific goal). Instead, they make decisions about their sacred values using a rule-bound and emotionally arousing moral logic that is insensitive to quantity and resists material trade-offs. ${ }^{10-13}$ Moreover, once people decide to engage in violent conflict in defense of such values, their moral commitment to violence may itself become a sacred value. ${ }^{14}$

The difference between devoted actor and rational actor perspectives does not concern the familiar cognitive limitations on rational information processing, ${ }^{15-17}$ which may be exacerbated by stressful situations in times of conflict. ${ }^{18,19}$ Rather, devoted actors treat sacred values as being above 
utility calculations and may make decisions that appear absurd when viewed through the lens of the rational-actor model. In previous work, we and others have provided empirical support from realworld conflict areas for several ways in which devoted actors driven by sacred values deviate from rational actors in their willingness to sacrifice selfinterest, including (1) violation of transitivity in preferences; $;^{20,21}(2)$ insensitivity or reverse sensitivity to quantity; ${ }^{14,22,23}$ (3) immunity to trade-offs ${ }^{24,25}$ coupled with a backfire effect, where offers of material incentives or disincentives to give up sacred values lead to emotional retrenchment-including anger, disgust and moral outrage-and heightened refusal to compromise or negotiate; ${ }^{11,26-29}$ (4) a rule-bound logic of moral appropriateness to do what is morally right no matter the likely risks or rewards; $;^{30-33}$ and (5) brain-imaging patterns consistent with processing sacred values as rules rather than as calculations of costs and consequences, and with processing perceived violations of sacred values as emotionally agitating. ${ }^{34,35}$

A key difficulty in motivating and sustaining collective action in the long run involves immunizing the group from individual defections. Monitoring and punishment of free riders and norm violators provides one set of means; ${ }^{36}$ however, a punishment regime is often costly to maintain and does little to eliminate inducements to defect that become attractive whenever and wherever vigilance is lax. ${ }^{37}$ Work on religious rhetoric and rituals suggest that these aspects of religion help to bind group members to long-term mutual commitments by internalizing religious beliefs into values adhered to through selfpolicing. ${ }^{38,39}$ Once internalized, such values appear to be less subject to the pressures and enticements of the here-and-now, such as the opinion of others and the lure of short-term goals and advantages. ${ }^{40}$ Accordingly, in this current work we seek to test and confirm these conjectures beyond the purely religious realm, by providing preliminary evidence for three additional and complementary characteristics of devoted actors driven by internalized sacred values, namely resistance to (1) social influence, (2) temporal discounting, and (3) exit strategies. We hypothesize that internalized sacred values should be less susceptible to social and temporal pressures than other socially, politically, or morally important values and norms. Moreover, sacred values should be relatively immune to personally beneficial in- ducements to trade off or give up those values, even if those inducements include implementation of other important values and norms. A successful demonstration of these ideas will also illuminate novel ways in which sacred values affect the decision making of devoted actors, and prolong intergroup conflicts.

The divide between the sacred and the profane has drawn the interest of social scientists for some time. $^{42-44}$ But until recently, research in judgment and decision making has concerned itself almost exclusively with how people make decisions in the profane or nonsacred domain, such as economic decision making. Over the last decade, more attention has been paid to how people form judgments and make decisions over sacred, compared to economic, values. ${ }^{6,24}$ A sacred value might be operationally defined as anything that people refuse to treat as fungible with material or economic goods, for example when people refuse to compromise over an issue regardless of the costs or benefits. ${ }^{11}$ Sacred issues may be religious but often are not, ${ }^{10}$ and research shows that issues without obvious religious content may be sacralized. ${ }^{45}$ While some have suggested that sacred values may be easily reneged in the face of material pressures ${ }^{25}$ history suggests otherwise. People will burn themselves alive, kill, and risk the lives of their families and loved ones in the name of a sacred values like "nation," "communism," "democracy," or "god."

Just as many things can be construed in moral versus nonmoral terms with consequences for judgment and decision making, ${ }^{40}$ so too many things can be both everyday aspects of life and sacred values depending on context: for instance, the Ganges can be a place to bathe and a holy body of water, Jerusalem can be a place to live and a holy city. The parallel with moral construal suggests possible communalities between sacred values and moral convictions, ${ }^{41}$ which have yet to be explored empirically. One strength of our conceptualization, however, is that sacred values are clearly circumscribed because they are narrowly defined.

Empirical research conducted in real-world political conflict demonstrates some ways in which sacred values can influence human conflict. Ginges et al. ${ }^{11}$ found, in a series of studies in the West Bank and Gaza, that adding material incentives to peace deals that involve compromises over sacred values can backfire. They presented Israeli 
settlers and Palestinians with realistic peace deals that offered a two-state solution, but also included compromises over issues that were considered sacred by many of the participants such as the right of return (for Palestinians) and giving up land (for Israeli settlers). All participants were presented with deals exchanging an important value for peace. Using a between-subjects experimental design, some participants were presented with this straightforward deal (e.g., "land for peace"), other participants were given some type of added material offer to sweeten the deal (such as money to help their nation or the promise of a life free of violence). If the deal did not invoke a participant's sacred value (as with Israelis for whom land was not sacred) the deal was still painful (most did not agree to it), but economic incentives produced the expected result: the material sweetener decreased anger, disgust, and support for violent opposition to the deal. In contrast, if the deal did invoke a value sacred to participants, they responded negatively to the materially improved deal; that is, the material sweetener increased anger, disgust, and support for violent opposition.

The backfire effect has been replicated in other contexts (for reviews, see Refs. 10, 12, and 14), such as Iran (nuclear energy program ${ }^{27,28}$ ), Indonesia $\left(\right.$ Sharia law $\left.^{23}\right)$, and the Muslim-Hindu conflict in India (around Babri Masjid and Kashmir ${ }^{29}$ ). This effect makes sense, considering Durkheim's ${ }^{43}$ observation that "the sacred and the profane are always and everywhere conceived by the human intellect as separate genera... the mind experiences a deep repugnance about mingling" the sacred and the profane (p. 36).

Other research demonstrates that when political violence is perceived to be morally mandated, as when sacred values are threatened or violated, support for violence can become a sacred value. When this happens, people demonstrate the same type of judgments and decisions about political violence as they do about other sacred values. Their support for violent action is insensitive to the scope of success, ${ }^{12}$ whether this refers to the number of hostages that might be rescued through the use of force, ${ }^{14}$ or the number of the enemy that might be killed. ${ }^{20}$ In one experiment, Palestinian participants intuitively believed it was inappropriate for the family of a martyr to request financial compensation, and the more compensation a hypothetical family requested, the more inappropriate the request was seen as being - a finding reminiscent of the backfire effect. ${ }^{20}$

In this article, we describe two studies conducted in the West Bank and Gaza that add to the emerging picture of how sacred values shape human conflict in a way that contributes to its continuation. In Study 1 , we explore the topic of social influence, asking if devoted actors, this is, people who consider a given issue in a conflict (e.g., right of return) as sacred, are less likely to be swayed by social influence, such as changing public support for their sacred value. In Study 2, we investigate if devoted actors experience events related to their existential conflicts, whether negative events in the past (e.g., tragic defeat) or positive events in the future (e.g., expected victory), as closer in time than other historical events, effectively diminishing temporal discounting. We also probe to see if sacred values blind devoted actors to possible ways of exiting the conflict.

\section{Study 1: Sacred values are resistant to social influence}

In intergroup conflicts, actors are subject to different forms of social influence as stakeholders attempt to influence each other. On the one hand, one group might try to intimidate the other into reprioritizing conflict-relevant issues. On the other, militants might be subject to in-group pressures to give up certain values in exchange for a more peaceful existence. One established finding within social psychology concerns the way people tend to conform to the opinions and beliefs of group members, even when those opinions are clearly incorrect. ${ }^{47-49} \mathrm{Peo}-$ ple can also be influenced by out-group opinion. For example, Malhotra and Ginges ${ }^{50}$ showed that the willingness of Israelis to vote for a peace deal was influenced both by the extent to which other Israelis supported the deal, and the level of agreement between Israeli and Palestinian opinion about the deal. Voting intentions were highest when both sides believed the deal was good or bad. The effect was mediated by perceived deal implementability, suggesting that people believed that balanced outcomes (both sides win or lose in equal measure) were more likely to lead to peace. Thus, people in conflict situations may also be influenced by the opinion of the other side.

In this experiment, we investigated whether the sacredness of issues in conflict may be relatively less vulnerable to social influence. Our experiment 
focused on an issue that we believed, based on discussions with Palestinian leaders, might prove to be an emerging sacred value for the Palestinian people; that of Palestinian sovereignty over the borders and airspace of a future Palestinian state (sovereignty). We asked participants to rank order the importance of eight virtues including this value. Before ranking, participants were exposed to an experimental manipulation where they were reminded of (1) the conflict with Israel in general (control condition), (2) Israeli rejection of Palestinian sovereignty over borders and airspace, or (3) Palestinian support for this issue. We predicted that for those who do not claim this value as sacred, its relative ranking would be influenced by in-group and out-group opinion. In contrast, devoted actors (i.e., those who do claim the value as sacred) would be relatively resistant to social influence (Hypothesis 1a). We also included an already normative sacred value in this study: the right of Palestinian refugees to return (right of return). The right of return has been a central tenet of the Palestinian independence movement since its inception. In previous studies we found that offering material incentives to give up this value backfired both for devoted actors and for people who did not categorize it as a sacred value. ${ }^{11}$ Thus, we predicted that the relative ranking of this established sacred value would be more resistant to social influence for nondevoted actors than the ranking of the emerging value of sovereignty (Hypothesis 1b).

\section{Methods}

\section{Participants}

We surveyed a representative sample $(n=1200)$ of Palestinians in the West Bank and Gaza with the help of the Palestinian Center for Policy and Survey Research (PCPSR). The sampling procedure went through three stages: first, population locations (clusters or counting areas) were randomly drawn using probability proportionate to size; second, households from these locations were randomly selected; third, one person was selected randomly from persons over 18 years in these households using Kish household tables. This sampling method leads to a self-weighting sample, which is representative of the population. Participants were interviewed at home, face to face; they were on average 38 years old (ranging from 18 to 87 years); half of them were women (51\%). Sixty-five percent lived
Table 1. Values and proportion of participants considering them sacred

\begin{tabular}{ll}
\hline Value & Sacred \\
\hline Belief in God and Mohammed (pbuh) & - \\
$\quad$ as His Prophet & - \\
Jihad against our enemies & $91 \%$ \\
Protecting the family & $86 \%$ \\
Fairness to others & $78 \%$ \\
Living by Sharia law & $78 \%$ \\
Defending the right of return & $86 \%$ \\
Protecting Palestinian rights over & \\
$\quad$ Jerusalem & $84 \%$ \\
Sovereign rights over Palestinian & \\
$\quad$ airspace and borders &
\end{tabular}

in the West Bank while the other 35\% lived in Gaza; $45 \%$ self-identified as refugees.

\section{Measures}

Sovereignty and the right of return are both important values for Palestinians; in fact they are sacred for most Palestinians. Asking them about the importance of these values directly would lead to a ceiling effect. To address this issue, we pitted these values against other values (e.g., protecting your family), which also are sacred for most Palestinians (see Table 1 for a complete list). We asked participants: "Which of these things do you feel Palestinians should value the most? Please rank in order of importance the following things (use " 1 " as the most important and " 8 " as least important; if more than one item has the same importance in your mind, then give those items the same rank number)." This measure allowed us to assess the importance of our target values relative to other important values. Effectively, participants were required to make a tradeoff between values important to them, resulting in a measure of relative (as opposed to absolute) importance of the target values. However, participants could assign the same rank to values they considered equally important.

\section{Procedure}

We ran our experiment within a larger survey on political attitudes and opinions. Participants were randomly assigned to one of only five conditions ( $n=240$, each): we asked participants about their opinion on either the Israeli-Palestinian conflict in general (control), Palestinians' support 
of control over borders and airspace (sovereignty: in-group support) and Israeli opposition to this demand (sovereignty: out-group opposition) and Palestinians' support of the right of return (return: in-group support) and its rejection by Israelis (return: out-group opposition) to test Hypothesis 1a. In the control condition, participants were asked to "Please think about the conflict between Palestine and Israel today. Which of these following words best describe how you feel when thinking about the conflict?" They were then given a list of emotion words (e.g., sadness) to pick from. In the "in-group support" conditions, participants were told: "As you know, Palestinians feel very strongly about [securing the refugees right to return to their original lands, towns, and villages/reclaiming Palestinian sovereignty over their own airspace and borders]." They were then asked how they felt about Palestinian support of the given issue. Similarly, in the "out-group opposition" conditions, participants were told: "As you know, the Israelis feel very strongly [about Palestinians' right of return and have rejected it since the creation of Israel/that they need to deny Palestinian control over the airspace and borders of Palestine]." They were then asked about their feelings about this opposition by Israelis.

Subsequently, we presented participants with a filler question, which was not analyzed: they were asked to rank a number of public figures according to whether Palestinian children should admire them as heroes (ranging from populists like Ahmadinejad to sportsmen like Ronaldinho). We then presented them with our measure of the relative importance of sovereignty and right of return (described above). In a different part of the survey we assessed if these values were sacred for the participant following Baron and Spranca's approach: ${ }^{24}$ we asked them to indicate if "in extreme circumstances it would be permissible for Palestinians to compromise" on the value. They were given the following options to respond: "I think this definitely needs to happen," "I do not object to this," "I think this should be done only if it brings great benefits," "I think this should be done only to avoid some great loss," and "This shouldn't be done no matter how great the benefits or losses." Participants were categorized as considering a given value as sacred when they picked the last option, leading to a dichotomous measure of sacredness. We did not assess sacredness of "belief in god and Mohammad (pbuh) as his prophet" and "jihad against our ene- mies" to prevent offense and to protect our participants, because admitting to compromise on these values could amount to admitting to be a heretic or a traitor.

\section{Results and discussion}

\section{Emotions}

Across all conditions, the most common emotions reported by the participants were sadness $(23 \%)$, anger $(21 \%)$, and humiliation (19\%). Emotional reactions differed significantly across conditions $\left(\chi^{2}(32)=441.9, P<0.001\right)$. While sadness was the most common emotion reported in the control condition (30\%), participants in both "in-group support" conditions reported happiness most frequently ( $27 \%$ for sovereignty, $30 \%$ for return). Participants in the "return: out-group opposition" condition reported anger most frequently (35\%), while the most common emotion in the "sovereignty: outgroup opposition" condition was humiliation, although anger was almost equally as common (30\% and $29 \%$, respectively).

\section{Sacredness}

A large majority of participants considered the given values sacred (see Table 1). In the absence of a manipulation (i.e., in the control group), sacredness was not related to gender, West Bank versus Gaza, or age, with one exception: the likelihood of considering sovereignty sacred increased with age ( $r=$ $0.195, P<0.002)$. Our manipulation did not affect sacredness: The proportion of people who considered sovereignty sacred did not differ significantly between control group, "sovereignty: ingroup support," and "sovereignty: out-group opposition" conditions $\left(\chi^{2}(2)=0.642, P=0.726\right)$. Nor did the proportion of people who considered the right of return sacred differ significantly between control group, "return: in-group support," and "return: out-group opposition" conditions $\left(\chi^{2}(2)=\right.$ $0.810, P=0.670)$. We tested if those values that were considered sacred were also perceived as relatively more important than nonsacred values. For this purpose, we calculated the average rank of sacred values and nonsacred values for each participant in the control group only, because in the experimental groups the rankings were affected by our manipulation. We then ran a paired sample $t$-test on these means: participants perceived their sacred values to be half a rank more important $(M=3.02$, 


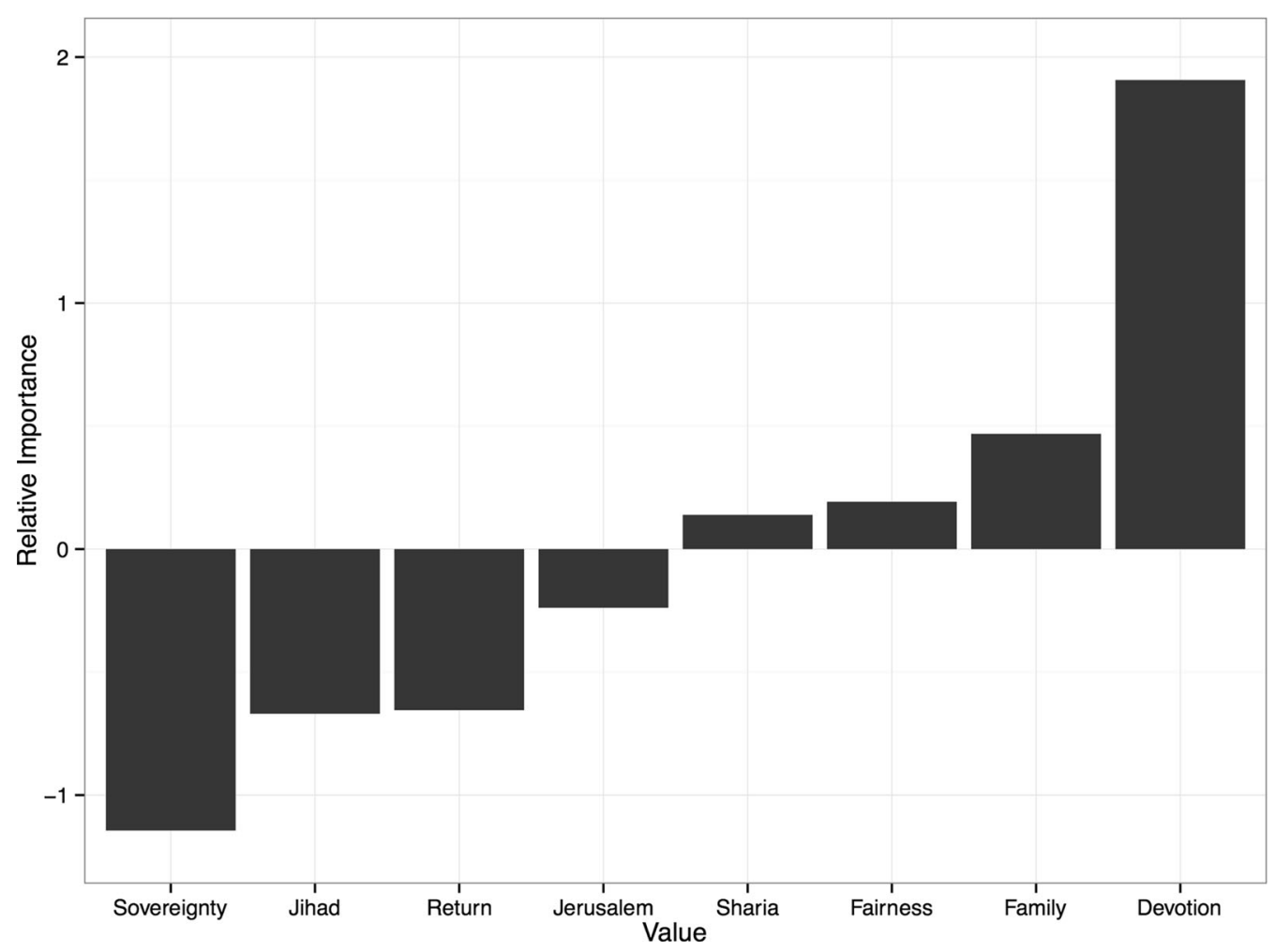

Figure 1. Relative importance of values in the control group.

$\mathrm{SD}=1.91)$ than their nonsacred values $(M=$ $3.52, \mathrm{SD}=2.17, t(112)=3.181, P_{\text {one-tailed }}=0.001$, $d=0.30$ ). Note that a difference score between the ranks of sacred and nonsacred values could only be calculated for a participant who had at least one sacred value and at least one nonsacred value. For that reason, the sample size for this $t$-test was $n=113$ out of the 240 participants in the control group.

\section{Relative importance}

Before analysis, we converted the ranks assigned by each participant to a measure of the relative importance of any given value. For each participant, we contrasted the rank of each value with the average rank of all other values to arrive at a measure of the relative importance of the value. For example, if a participant assigned sovereignty a rank of 6 , and the ranks of the remaining seven values averaged 4.5 , the relative importance of sovereignty for this participant was -1.5 (i.e., 4.5-6). In other words, this participant ranked sovereignty as 1.5 ranks less important than the remaining seven values taken together. This resulted in a measure easy to inter- pret, with higher scores indicating higher relative importance compared to the other values.

In the absence of a manipulation, Palestinians perceived social values (e.g., protecting one's family) as more important than political ones (e.g., right of return), with sovereignty being the least important one (see Fig. 1). The relative importance of the given values was not correlated with the gender or age of the participants. However, participants living in Gaza considered "jihad against our enemies" as more important than those living in the West Bank $\left(M_{\text {diff }}=0.70, \mathrm{SD}_{\text {pooled }}=2.02, t(234)=2.552, P=\right.$ $0.012, d=0.35)$, but they regarded "living by Sharia law" as less important $\left(M_{\text {diff }}=0.52, \mathrm{SD}_{\text {pooled }}=1.68\right.$, $t(234)=2.296, P=0.023, d=0.31)$.

Table 2 provides the means of the relative importance of sovereignty and right of return across conditions. To test our hypotheses about the effect of social influence on the relative importance of sacred values, we ran two regressions. For Hypothesis 1a, we ran a regression model of the relative importance of sovereignty predicted by four dummycoded variables for the experimental conditions 
Table 2. Means (SD in parentheses) of relative importance of sovereignty and right of return across conditions

\begin{tabular}{llll}
\hline & Control & In-group support & Out-group opposition \\
\hline Sovereignty & & & $-0.84(1.70)$ \\
$\quad$ Sacred & $-0.97(1.72)$ & $-0.91(1.95)$ & $-0.59(1.86)$ \\
$\quad$ Not sacred & $-1.93(1.95)$ & $-0.97(1.59)$ & $-0.50(1.56)$ \\
Right of return & & $-1.05(1.66)$ & $-0.64(1.54)$ \\
$\quad$ Sacred & $-0.92(1.74)$ & $-0.55(1.87)$ & \\
$\quad$ Not sacred & $-0.59(1.60)$ & & \\
\hline
\end{tabular}

(with control group as the comparison): sacredness of sovereignty (dummy coded 0 for nonsacred and 1 for sacred), as well as the interaction terms of "sacredness" and the four dummy-coded variables for the experimental conditions $(F(9,1174)=1.908$, $P=0.047, R^{2}=0.014$; see Table 3 for regression coefficients).

In line with Hypothesis 1a, the interaction terms of sacredness of sovereignty and both sovereignty conditions were significant: devoted actors, that is, those who considered sovereignty a sacred value, were not affected by the experimental conditions; nondevoted actors, however, perceived sovereignty as more important when they were reminded of support by fellow Palestinians or of opposition by Israelis (Fig. 2). This finding was robust even when age, gender, West Bank versus Gaza, and the emotional reaction to the manipulations were entered as controls.

To test Hypothesis 1b, we first ran a regression of the relative importance of right of return predicted by dummy-coded variables for the experimental conditions, sacredness of right of return, and the interaction terms between sacredness and the dummy-coded variables for the experimental conditions. This regression model did not significantly explain the variance in the relative importance of right of return $(P=0.494)$. Thus, the socialinfluence manipulation did not affect the relative importance of right of return.

Overall, these findings suggest that sacred values are relatively immune to social influence. Palestinians were not swayed by support by fellow Palestinians for the established sacred value of the right of return, nor by Israeli opposition to it. Similarly, those who held the emerging sacred value of sovereignty over airspace and borders as sacred were also immune to social influence. However, people who did not consider sovereignty sacred did perceive it as more important when it was supported by fellow Palestinians or opposed by Israelis.

This relative immunity of sacred values to our manipulations contrasts with the rational-actor perspective, which would predict in-group support to increase the importance of a value but any kind of opposition to decrease it, especially Israeli opposition because it is associated with considerable cost for Palestinians. Interestingly, even for those who were susceptible to social influence, Israeli opposition did not decrease the importance of sovereignty, but increased it instead. We speculate that both our experimental manipulations increased group cohesiveness, ${ }^{51}$ which in turn may have led nondevoted actors to commit more to group interests. Devoted actors, on the other hand, may already be aligned with the group (identity fusion ${ }^{52}$ ) and thus not be affected by group cohesion.

An ongoing set of brain-imaging studies suggests that there may be neural correlates to the resistance of sacred values to social pressure. ${ }^{39}$ In a follow-up to an earlier study, ${ }^{38}$ experimenters introduced a social-influence manipulation at the stage of the study when people (in this case, American college students) are asked to choose which value statements they identify with (e.g., "I believe in God"). Subjects could see the percentage of fellow participants who agreed with them for each statement (i.e., subjects see a "thermometer" consisting of a column of five circles, where each halffilled circle represents 10\% social support from the subject's reference population). The study showed that willingness to change positions on an issue to reflect majority opinion was negatively correlated with activation of the ventrolateral prefrontal cortex (associated with rule processing) and the amygdala (associated with emotional agitation) the same brain regions activated for sacred values in Ref. 34. 
Table 3. Regression of relative importance of sovereignty on conditions and sacredness of sovereignty

\begin{tabular}{lrrrr}
\hline & \multicolumn{1}{c}{ SE } & \multicolumn{1}{c}{$t$} & \multicolumn{1}{c}{$P$} \\
\hline Intercept & -1.932 & 0.280 & -6.908 & $<0.001$ \\
Sovereignty: in-group support & 0.965 & 0.415 & 2.325 & 0.020 \\
Sovereignty: out-group opposition & 1.341 & 0.412 & 3.257 & 0.001 \\
Right of return: in-group support & 0.864 & 0.396 & 0.184 & 0.029 \\
Right of return: out-group opposition & 0.793 & 0.415 & 3.107 & 0.053 \\
Sovereignty sacred & 0.959 & 0.309 & -1.541 & 0.002 \\
Return in-group support X sacred & -0.672 & 0.436 & -1.474 & -1.997 \\
Return out-group opposition X sacred & -0.660 & 0.448 & -2.692 & 0.141 \\
Sovereignty in-group support X sacred & -0.905 & 0.453 & 0.450 & 0.007 \\
Sovereignty out-group opposition X sacred & -1.212 & & & 0.007 \\
\hline
\end{tabular}

Study 2: Sacred values decrease perceived temporal distance and constrain choices

We designed a study to test ideas concerning two additional and complementary ways in which sacred values may influence intergroup conflict: resistance to temporal discounting and constraining choices to exit the conflict.

Differences in perceived temporal distance and temporal discounting may indicate which values engender greater devotion than others. Much of the work on temporal judgment has focused on single hypothetical events that are close or far away within a fairly limited past or future time span (e.g., previous or next day versus last or next year). ${ }^{53,54}$ We know little concerning distance dynamics and associated consequences when there is a date or event that takes on symbolic or sacred significance (e.g., the year of Christ's birth or Mohammed's flight from Mecca to Medina), a salient precedent (e.g., the Crusades, the Holocaust, 9/11), or a future concrete goal (e.g., an independent Kurdish state, a government ruled by Sharia law). A complementary measure of devotion to sacred values is unwillingness to abandon such values for other normatively important values, even when those other values incur less personal risk, provide more direct personal advantage, and carry important social benefits appreciated by the community.

Many decisions require a weighing of costs and benefits at different points in time. For instance, political leaders may have to trade off the implementation of a disputed but important policy (with great benefits in the future) with the risk of losing support of their constituency now. In such situations, people have a tendency to discount the value of costs and benefits the farther they are away from the present (e.g., in a distant future or distant past). In the context of intergroup conflict, negative events in the past (such as a tragedy befalling one's people) may be more effective in motivating action if people feel closer to those events. Likewise, positive future events may motivate action more if they are seen as closer at hand and more likely to occur. We tested the idea that devoted actors, who construe issues in a political conflict as sacred, may feel temporarily closer to sacred past and future events, effectively counteracting temporal discounting (Hypothesis 2a).

Additionally, we tested the idea that sacred values may contribute to the continuation of conflicts by constraining choices of devoted actors, so they are more likely to reject individual exit strategies, even when those strategies are framed in terms of duties to the nation or to religion (Hypothesis 2b). We tested both of these hypotheses within one survey of Palestinian adolescents.

\section{Methods}

We conducted a survey with a representative sample of Palestinian adolescents in the West Bank and Gaza ( $n=555$, ages $11-19$ years, cohorts 12,15 , and 18 years, $50 \%$ female), again in cooperation with the PCPSR. The sample procedure was identical to the one used in Study 1, with the exception that instead of an adult, a child was selected randomly from each household. All questions were tested for comprehension in a pilot study with adolescents in the same age range. Similar to Study 1, participants were interviewed at home, face to face, in Arabic by trained Palestinian interviewers. The relevant measures were embedded in a larger survey on 


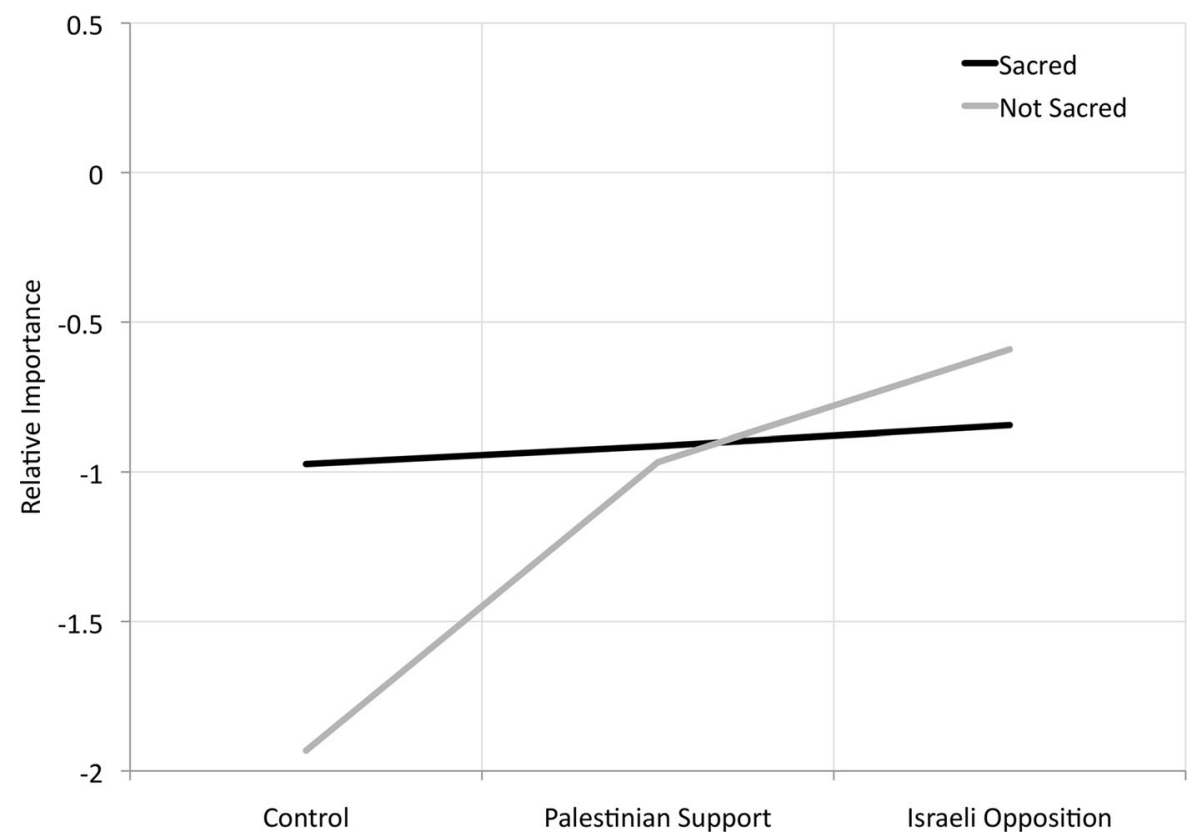

Figure 2. Importance of sovereignty with perceived in-group support or out-group opposition.

political opinions, as part of which they were asked if they consider three core issues of the conflict as sacred (Jerusalem, right of return, recognition of Israel) using the same measure as in Study 1.

\section{Hypothesis 2a: temporal distance}

To assess if sacred values change the perception about the distance of relevant events, we asked participants how close the Nakba ("Catastrophe," referring to the exodus of Palestinians as a result of the foundation of Israel in 1948) felt to them (from $1=$ "feels like yesterday" to $10=$ "feels like distant past") and how many years ago it happened. As a point of comparison, we also asked them the same questions about the end of World War II (an event unlikely to invoke sacred values for our participants). For a future event, we also asked them to estimate how many years they thought it would take until Palestinians could "return to their former lands" in what now is Israel.

\section{Hypothesis 2b: exit strategies}

We presented our participants with two scenarios allowing them to escape violent conflict. We framed options in terms of some type of moral virtue to allow participants to think about exit strategies that would save face. Participants were told to imagine that there had been an invasion of "Israeli invasion forces and a resistance is being organized." They were then presented with an exit strategy: we asked them if given the opportunity they would "make a Hajj to Mecca instead of staying to resist." Subsequently, they were asked to imagine the same situation but this time with an opportunity to go "overseas to participate in a training program so that you can come back and serve your country." Participants indicated if they would "seriously think about" taking the opportunity (response options: "yes," "no," "don't know").

\section{Results and discussion}

\section{Hypothesis 2a: temporal distance}

The majority of our participants $(84 \%)$ considered the right of return as sacred. On average, participants felt moderately close to the Nakba $(M=4.66$, $\mathrm{SD}=2.97)$, and they perceived the end of World War II as more distant than the Nakba $\left(M_{\text {diff }}=\right.$ $1.88, \mathrm{SD}_{\text {diff }}=3.22, t(505)=13.135, P<0.001, d=$ $0.58)$. While the temporal distance to the Nakba was not related to the gender of the participants, older participants perceived the Nakba to be closer $(r=$ $-0.144, P<0.001)$. Also, participants living in Gaza perceived the Nakba as closer than did those living in the West Bank $\left(M_{\text {diff }}=0.82, t(545)=3.173, P=\right.$ $0.002, d=0.28$ ). 
To test Hypothesis 2a, we ran an ANCOVA with temporal distance to the Nakba as dependent variables, sacredness (dichotomous: whether participant considered right of return sacred or not) as an independent variable, and temporal distance to World War II as a covariate. There was a significant effect of the covariate on the distance to the Nakba $(F(1,503)=85.493, P<0.001)$. Not surprisingly, participants who felt closer to the end of WWII also felt closer to the Nakba. In line with Hypothesis 2a, there was a significant effect of sacredness on the distance to the Nakba $(F(1,503)=5.206, P=0.023)$. Controlling for the distance to World War II, devoted actors felt $M_{\text {diff }}=0.73$ points closer to the Nakba compared to those who did not consider the right of return as sacred. This finding was robust even when age, gender, and West Bank versus Gaza were entered as controls.

Asked to estimate the years that have passed since the Nakba, a majority of participants gave an estimate very close to the correct amount of years (i.e., 63 years). Nevertheless, we conducted the same analysis as above, this time with years since the $\mathrm{Nakba}$ as the dependent variable. Again, there was a significant effect of the covariate $(F(1,452)=$ $31.816, P<0.001)$. The more years participants thought had passed since the end of World War II, the more years they thought had passed since the Nakba. However, controlling for the years since the end of World War II, there was no significant effect of sacredness, $P=0.965$ : devoted actors did not differ from others when it comes to their estimates of the years that have passed since the Nakba.

Asked in how many years Palestinians will be able to return to their former lands, participants had the option to indicate "never." Devoted actors were significantly less likely to respond "never" (17\%) than those who did not consider the right of return as sacred $\left(26 \%\left(\chi^{2}(2)=3.052, P_{\text {one-tailed }}=0.040\right)\right)$. Among those who did expect Palestinians to return, devoted actors estimated that Palestinians will be able to return earlier $(M=15.79, \mathrm{SD}=20.11)$ than those who did not consider the right of return as sacred $(M=20.65, S D=23.40)$. This effect was only marginally significant $\left(t(358)=1.594, P_{\text {one-tailed }}=\right.$ 0.056). Nevertheless, we can have fairly high confidence in this finding inasmuch as it did not include the people who thought Palestinians will never re- turn to their former lands, and the proportion of such people was lower in devoted actors than in nondevoted ones.

Together the findings show that devoted actors feel that events related to their sacred values are closer to them, be they past or future events. This effect does not stem from a factual mistake on when past events took place historically, as devoted actors recalled the correct numbers of years since the Nakba just as well as others did. These results suggest that sacred values counteract the effects of temporal discounting on decision making over associated events. Additionally, sacred values may lead to shrinking, disappearance or even reversal of standard effects of psychological distance on preferences and actions (construal level theory ${ }^{53}$ ) for objects, events, and persons associated with sacred values.

\section{Hypothesis 2b: exit strategies}

Turning down opportunities to exit the conflict is not tied to specific sacred values, like the right of return. Therefore, we compared moral absolutists, that is, those who held all issues we assessed (East Jerusalem, right of return, and recognition of Israel) as sacred values (in our sample, $76 \%$ ) to those who considered two or fewer of these issues sacred. Moral absolutists were significantly more likely to refuse making the Hajj over resisting Israeli occupation (75\%) than those who did not consider all issues sa$\operatorname{cred}\left(61 \%\left(\chi^{2}(2)=3.524, P_{\text {one-tailed }}=0.030\right)\right)$. Similarly, the likelihood that moral absolutists would refuse going abroad for training instead of joining the resistance $(65 \%)$ was significantly higher than of nonabsolutists $\left(56 \%\left(\chi^{2}(1)=9.364, P_{\text {one-tailed }}=\right.\right.$ $0.001)$ ).

In summary, compared to those who did not consider the right of return as sacred, devoted actors did feel closer to the Nakba than to the end of World War II. They also considered it more likely that Palestinians will return to their former lands in what now is Israel, and they expected this return to occur earlier. Moral absolutists (those who considered all of the issues as sacred) were also more likely to refuse opportunities to exit the conflict (and abandon resistance to Israeli occupation) than were nonabsolutists, even if the opportunities would also morally serve God (Hajj) or country (training), but in ways unrelated to conflict. 


\section{Discussion}

In developing a more comprehensive picture of sacred values, we hypothesized that for devoted actors driven by such values under conditions of conflict, there would be resistance to social influence, temporal discounting, and exit strategies (based in part on theoretical arguments developed in Ref. 10). We examined data for the Palestinian case and found confirmation of our hypotheses. Future research will determine whether our hypotheses also hold for Israelis on the other side the conflict, as we expect given our previous research showing parallel attachments to sacred values on both sides of the Israel-Palestine divide with regard to immunity to trade-offs, the backfire effect, insensitivity to quantity, and so forth. ${ }^{11,26,54}$ Our previous research (reviewed in Ref. 12) also lead us to anticipate that findings for the Israel-Palestine conflict may well extend to other cultural and political contexts involving deep-seated intergroup conflict.

In Study 1, we found that when people hold a value to be sacred, and behave as devoted actors on issues related to that value, the priority they give the value is relatively resistant to social pressure. In Study 2, we found preliminary evidence that for events associated with sacred values, the psychological perception of temporal distance can shrink significantly: Palestinians who viewed the right of return to their former lands as sacred (compared to other Palestinians) perceived the Nakba to be temporally closer than the end of World War II. They also estimated the time when a return will be possible to be closer. These findings suggest the possibility that, even as implementation of sacred values is delayed (perhaps by political leaders and devoted activists) in order to meet responsibilities, the psychological distance to those values may remain small, ensuring that commitment to them does not fade.

Finally, we found that devoted actors were significantly less likely than nondevoted actors to express willingness to take an opportunity to exit the conflict: Palestinians who considered core issues of the conflict as sacred were reliably less inclined to abandon or delay their duty to resist occupation in exchange for acting in accordance with a sacred value unrelated to personal risk or group threat (undertaking the Hajj) or for accomplishing an action considered important but not sacred (personal training to better serve the country). Notice that our test of exit strategies involved inducements internal to the group. We expect future research to show that inducements offered by out-groups will be even less attractive, no matter how lucrative or beneficial to the person.

These new findings complement previous work demonstrating the way sacred values can influence the trajectory of intergroup conflict. In previous laboratory experiments, including brain imaging studies — supported by field work with political leaders, revolutionaries, terrorists, and others-we have shown sacred values to be at the core of personal and social identity ("who I am" and "who we are"). ${ }^{10,13,34,46}$ Sacred values appear to be processed as moral rules, duties, and obligations that defy the utilitarian and instrumental calculations of realpolitik or the marketplace. Findings indicate that sacred values are immune to material trade-offs and insensitive to quantity (e.g., God loves equally a martyr who kills 100,1000 , or none of the enemy because it is the commitment to the cause that counts). ${ }^{23,32}$ Sacred values also have privileged links to emotions, such as anger and disgust at their violation, leading to moral outrage and increased support for violence. ${ }^{11,20,21,35,55,56}$ People defending a sacred value will resist trading it off for any number of material benefits, or even for peace.

The sacred values of devoted actors, it turns out, generate action independent of calculated risks, costs, and consequences-a direct contradiction of prevailing rational-actor models of politics and economics, which focus on material interests. Devoted actors, in contrast, act because they sincerely and deeply believe "it's the right thing to do," regardless of risks or rewards. The difference concerns the distinct cognitive processes associated with the formation (and perhaps fusion, see Ref. 52) of personal and in-group identity among devoted actors, which places desired expectations that are associated with securing that identity-as a matter of moral conviction-above rational and calculated analysis of potential problems and flaws in a policy or decision. Practically, this means that devoted actors often harness deep and abiding social and political commitments to confront much stronger foes. Think of the American revolutionaries, who were willing to devote "our lives, our fortunes, and our sacred honor" in the fight for liberty against the greatest military power of the age, or modern 
suicide bombers willing to sacrifice everything for their cause. ${ }^{57}$

Sacred values-like the transformation of land into "Holy Land" - sustain the commitment of revolutionaries and militant groups to resist, and often overcome, more numerous and better-equipped militaries and police that function with measured rewards like better pay or promotion. Research with political leaders and general populations also shows that sacred values-not political games or economics-underscore intractable conflicts like those between the Israelis and the Palestinians that defy the rational give-and-take of businesslike negotiation. ${ }^{11,23,26-28}$ Field experiments in Israel, Palestine, Nigeria, and the United States indicate that commitment to such values can motivate and sustain wars beyond reasonable costs and casualties. ${ }^{14}$ Perhaps most importantly, this research helps to explain why efforts to broker peace that rely on money or other material incentives are doomed when core values clash. In our studies with colleagues in Afghanistan, India, Indonesia, Iran, the Levant, and North Africa, we found that offers of material incentives to compromise on sacred values often backfire, actually increasing anger and violence toward a deal. ${ }^{12}$

Leaders and activists, who are highly identified with the group and may perceive group interests as sacred values, may seek to deepen commitment to their sacred values among followers and the general population through cognitive and behavioral means that promote a deeper internalization of values so as to immunize them from normative influences. Our previous research suggests that whereas some conflicts start over issues that are considered historically sacred, initially mundane issues can become sacralized in protracted conflicts under conditions of heightened perceptions of threat, especially if these issues are also implicated in religious ritual and rhetoric. ${ }^{41}$ Thus, the very opposition by the international community and the sanctions imposed upon Iran, together with the Iranian regime's ratcheting up the psychological effects of this opposition with religious rhetoric, may be significant factors behind the fact that the Iranian nuclear energy program is emerging as a sacred value in Iran among a minority of the population, but one that is close to the regime and bound up through religious rhetoric with national identity and even Islam itself. $^{27,28}$
In sum, our previous research showed that heightened perception of outside threats and intensification of in-group religious ritual and rhetoric helps to sacralize disputed values. Here, we have presented findings that suggest that once values are sacralized and associated with conditions of intergroup conflict, people will adhere to them regardless of social pressures, considerations of time, or the benefits associated with other important values and available courses of action and exit. As Darwin noted in the Descent of $M a n,{ }^{58}$ for a given group in conflict with other groups, the key to victory is the willingness of at least some members to sacrifice even their lives (the totality of their self-interests) in an apparently irrational blindness to plausible exit strategies and alternatives. It is this commitment that we have associated in our research with sacred values: that is, the virtue of "morality ... the spirit of patriotism, fidelity, obedience, courage, and sympathy," which Darwin believed enabled groups endowed with such devoted actors to resist and triumph over other groups (even those with materially greater means) in history's spiraling competition for survival and dominance. Understanding the role of sacred values in the apparently intractable conflicts of today, in an era of globalized politics and weapons of mass destruction, may indeed be critical to our group welfare.

\section{Acknowledgments}

This research was supported by grants from the National Science Foundation (SES-0961997 and SES-0962080), the U.S. Army Research Office (W911NF0810301, grant to ARTIS Research), and the Office of Naval Research (MINERVA-ONR N000141310054, grant to ARTIS Research).

\section{Conflicts of interest}

The authors declare no conflicts of interest.

\section{References}

1. Collier, P., A. Hoeffler \& D. Rohner. 2009. Beyond greed and grievance: feasibility and civil war. Oxford Econ. Pap. 61: $1-27$.

2. Fearon, J. D. \& D.D. Laitin. 2003. Ethnicity, insurgency, and civil war. Am. Polit. Sci. Rev. 97: 75-90.

3. Ross, M.L. 2004. What do we know about natural resources and civil war? J. Peace Res. 41: 337-356.

4. Fearon, J.D. 2004. Why do some civil wars last so much longer than others? J. Peace Res. 41: 275-301. 
5. Meirowitz, A. \& A.E. Sartori. 2008. Strategic uncertainty as a cause of war. Quart. J. Polit. Sci. 3: 327-352.

6. Tetlock, P.E., O.V. Kristel, S.B. Elson, et al. 2000. The psychology of the unthinkable: taboo trade-offs, forbidden base rates, and heretical counterfactuals. J. Personal. Soc. Psychol. 78: 853.

7. Atran, S. 2006a. "Devoted Actor" versus "Rational Actor" Models for Understanding World Conflict, Briefing to the National Security Council, White House, Washington, DC, September 14; available at http://www.edge.org/3rd_ culture/atran06/atran06_index.html

8. Nyhamar, T. 1997. Rationality explanations: the case of Kissinger's decision to supply arms to Angola. Coop. Confl. 32: 181-205.

9. Martin, L. 1999. The contributions of rational choice: a defense of pluralism. Int. Secur. 24: 74-83.

10. Atran, S. \& J. Ginges. 2012. Religious and sacred imperatives in human conflict. Science 336: 855-857.

11. Ginges, J., S. Atran, D. Medin \& K. Shikaki. 2007. Sacred bounds on rational resolution of violent political conflict. Proc. Natl. Acad. Sci. 104: 7357-7360.

12. Ginges, J., S. Atran, S. Sachdeva \& D. Medin. 2011. Psychology out of the laboratory: the challenge of violent extremism. Am. Psychol. 66: 507.

13. Ginges, J. \& S. Atran. 2013. "Sacred values and cultural conflict." In Advances in Culture and Psychology. M.J. Gelfand, C.Y. Chiu \& Y.Y. Hong, Eds.: vol. 4. New York: Oxford University Press.

14. Ginges, J. \& S. Atran. 2011. War as a moral imperative (not just practical politics by other means). Proc. R. Soc. B 278: 2930-2938.

15. Becker, G. 1962. Irrational behavior and economic theory. J. Polit. Econ. 70: 1-13.

16. Simon, H. 1982. Models of Bounded Rationality. Cambridge, MA: MIT Press.

17. Kahneman, D. 2011. Thinking, Fast and Slow. New York: Farrar Giroux \& Strauss.

18. Jervis, R. 1976. Perception and Misperception in International Politics. Princeton: Princeton University Press.

19. Allison, G. \& P. Zelikow. 1999. Essence of Decision: Explaining the Cuban Missile Crisis, 2nd ed. New York: Longman.

20. Ginges, J. \& S. Atran. 2009b. What motivates participation in violent political action. Ann. NY Acad. Sci. 1167: 115-123.

21. Atran, S. 2010. Talking to the Enemy: Violent Extremism, Sacred Values, and What it Means to be Human. London: Penguin.

22. Sachdeva, S. \& D.L. Medin. 2008. "Is it more wrong to care less: the effects of more and less on the quantity sensitivity of protected values." In Proceedings of the 30th Annual Meeting of the Cognitive Science Society, CogSci 2008. Hillsdale, NJ: Earlbaum.

23. Ginges, J. \& S. Atran. 2009a. "Non-instrumental reasoning over sacred values: an Indonesian field experiment." In Psychology of Learning and Motivation, Vol. 50: Moral Judgment and Decision Making. D. M. Bartels, C. W. Bauman, L. J. Skitka \& D. L. Medin, Eds.: 194-206. San Diego: Academic Press.

24. Baron, J. \& M. Spranca. 1997. Protected values. Organ. Behav. Hum. Decis. Processes 70: 1-16.
25. Tetlock, P.E. 2003. Thinking the unthinkable: sacred values and taboo cognitions. Trends Cogn. Sci. 7: 320-324.

26. Atran, S., R. Axelrod \& R. Davis. 2007. Sacred barriers to conflict resolution. Science 317: 1039-1040.

27. Dehghani, M., R. Iliev, S. Atran, et al. 2009. Emerging sacred values: the Iranian nuclear program. Judgm. Decis. Mak. 4: 990-993.

28. Dehghani, M., S. Atran, R. Iliev, et al. 2010. Sacred values and conflict over Iran's nuclear program. Judgm. Decis. Mak. 5: 540-546.

29. Sachdeva, S. \& D.L. Medin. 2009. Group identity salience in sacred value based cultural conflict: an examination of the Hindu-Muslim identities in the Kashmir and Babri mosque issues. In: Proceedings of the 31 th Annual Meeting of the Cognitive Science Society, CogSci 2009. Hillsdale, NJ: Earlbaum.

30. Skitka, L.J. 2002. Do the means always justify the ends, or do the ends sometimes justify the means? A value protection model of justice reasoning. Personal. Soc. Psychol. Bull. 28: 588-597.

31. Hoffman, B. \& G. McCormick. 2004. Terrorism, signaling, and suicide attack. Studies Conf. Terrorism 27: 243-281.

32. Atran, S. 2006b. The moral logic and growth of suicide terrorism. Wash. Quart. 29: 127-147.

33. Bartels, D. \& D.L. Medin. 2007. Are morally motivated decision makers insensitive to the consequences of their choices? Psychol. Sci. 18: 24-28.

34. Berns, G.S., E. Bell, C.M. Capra, et al. 2012. The price of your soul: neural evidence for the non-utilitarian representation of sacred values. Philos. Trans. R. Soc. B 367: 754-762.

35. Berns, G.S., E. Bell, M. Capra, et al. 2013. Moral Outrage and the Neurobiological Antecedents to Political Conflict. Dayton, $\mathrm{OH}$ : Presented to AFOSR Annual Trust and Influence Review.

36. Boyd, R., H. Gintis \& S. Bowles. 2010. Coordinated punishment of defectors sustains cooperation and can proliferate when rare. Science 328: 617.

37. Vukov, J., F.L. Pinheiro, F.C. Santos \& J.M. Pacheco. 2013. Reward from punishment does not emerge at all costs. PLoS Comput. Biol. 9: e1002868.

38. Johnson, D. 2005. God's punishment and public goods: a test of the supernatural punishment hypothesis in 186 world cultures. Hum. Nat. 16: 410-446.

39. Fischer, R., R. Callander, P. Reddish \& J. Bulbulia. 2013. How do rituals affect cooperation? An experimental field study comparing ritual types. Hum. Nat. 24: 115-125. doi 10.1007/s12110-013-9167-y.

40. Paglieri, F., A. Borghi, L. Colzato, et al. 2013. Heaven can wait. How religion modulates temporal discounting. Psychol. Res.

41. Van Bavel, J.J., D.J. Packer, I.J. Haas, \& W.A. Cunningham. 2012. The importance of moral construal: moral versus nonmoral construal elicits faster, more extreme, universal evaluations of the same actions. PloS one, 7(11): e48693.

42. Skitka, L.J. 2010. The psychology of moral conviction. Soc. Personal. Psychol. Compass 4: 267-281.

43. Durkheim, E. 1995 (1912). The Elementary Forms of Religious Life. New York: Free Press.

44. Eliade, M. 1957. The Sacred and the Profane: The Nature of Religion. New York: Harcourt Brace Jovanovich. 
45. Rappaport, R.A. 1971. The sacred in human evolution. Ann. Rev. Ecol. Syst. 2: 23-44.

46. Sheikh, H., J. Ginges, A. Coman \& S. Atran. 2012. Religion, group threat and sacred values. Judgm. Decis. Mak. 7: 110118.

47. Asch, S.E. 1956. Studies of independence and conformity. I: a minority of one against a unanimous majority. Psychol. Monogr. 70: 1-70.

48. Cialdini, R.B. \& N. J. Goldstein. 2004. Social influence: compliance and conformity. Ann. Rev. Psychol. 55: 591-621.

49. Moscovici, S. 1985. Social influence and conformity. Handbook Soc. Psychol. 2: 347-412.

50. Malhotra, D. \& J. Ginges. 2010. Preferring balanced vs. advantageous peace agreements: a study of Israeli attitudes towards a two state solution. Judgm. Decis. Mak. 5: 420-427.

51. Cota, A.A., C.R. Evans, K.L. Dion, et al. 1995. The structure of group cohesion. Personal. Soc. Psychol. Bull. 21: 572580 .
52. Swann, W.B., J. Jetten, Á. Gómez, et al. 2012. When group membership gets personal: a theory of identity fusion. Psychol. Rev. 119: 441-456.

53. Fiedler, K. 2007. Construal level theory as an integrative framework for behavioral decision-making research and consumer psychology. J. Consum. Psychol. 17: 101-106.

54. Trope, Y. \& N. Liberman. 2010. Construal-level theory of psychological distance. Psychol. Rev. 117: 440-463.

55. Trope, Y. \& N. Liberman. 2010. Construal-level theory of psychological distance. Psychol. Rev. 117: 440-463.

56. Ginges, J. \& S. Atran. 2008. Humiliation and the inertia effect: implications for understanding violence and compromise in intractable intergroup conflicts. J. Cogn. Cult. 8: 3-4.

57. Atran, S. \& R. Axelrod. 2008. Reframing sacred values. Negotiation J. 24: 221-246.

58. Darwin, C. 1871. The Descent of Man, and Selection in Relation to Sex. London: John Murray. 